\title{
The College Students' Psychology and Education Management
}

\author{
Xiaojiao Liu \\ Tianjin University of Science and Technology, China \\ liuxiaojiao@tust.edu.cn
}

Keywords: College students, Psychological health, Education management.

\begin{abstract}
Higher education aims at developing high-quality person who is fully developed, including the all-round development of psychological qualities. However, many researches show that the psychological condition of college students is hardly optimistic. On the basis of the research of psychological health connotation as well as current situation of psychological health of the college students, the education management system of psychological health adapted to domestic college students should contain creating a good environment for psychological health education, establishing a high-quality psychological health education staff, setting up psychological health education curriculum, establishing and improving the students' psychological health records, enhancing the network security management system and creating a good campus culture in a wish to cultivate the talents with both professional knowledge and physical and psychological health for the country.
\end{abstract}

\section{Introduction}

College students are the future pillars of society, strengthening the psychological health education of college students is very important. We should pay attention to psychological health education, according to the characteristics of college students physical and psychological development and education law, pay attention to cultivate college students' good psychological quality and self-esteem, self-love, self-discipline and self-improvement of good character, strengthen the ability of college students to overcome difficulties, tested, withstand setbacks.

The Ministry of Education noted that the work to strengthen the psychological health education is an important measure to the full implementation of quality education and an important approach to promote the comprehensive development of college students. It can be seen that the state attaches great importance to college students' psychological health problems. Therefore, universities should strengthen the exploration and research of college students' psychological health education management system and actively explore a new model of education management in line with modern development law to promote the comprehensive development of students' quality.

\section{The Connotation of Psychological Health and College Students' Psychological Health Status}

In 1946, The World Psychological Health Congress noted: "Psychological health refers to the body, intelligent and emotionally to keep not inconsistent with others' psychology, and to develop personal mood into the best state.” [1] One sentence summary, college students' psychological health refers to the individual in the process of adapting to the environment, all aspects of physical, psychological, spiritual and social achieve coherence, and maintain good psychological state.

With the popularization of higher education, college students are no longer favored, they carry more conflict between ideal and reality. In the face of social change and the challenges of life, especially the pressure of various factors in economic, academic, emotional, interpersonal relationship and employment, leading to college students' psychological crisis has become increasingly prominent, and caused widespread concern in the schools and community. The survey showed that college students know little about psychological health knowledge, sometimes they put the psychological illness attributed to a bad mood. "Depression" has become the mantra of college students. The common heart health problems of college students are as follows: 
The Maladjustment of Interpersonal Relationships. Into the new campus environment, in the face of new learning and living environment, interpersonal problem almost became their biggest problem. Most students have a sense of loneliness, desire friendship and understanding, hope to establish good interpersonal relationship. However, they often lack the communication skills. Due to the high expectations and low achievement causing huge psychological gap. Over time, it will form a depression, social phobia and other psychological illnesses, thus they cannot seriously study, and take a more radical approach in severe cases.

Earning Maladjustment. University autonomy is strong, some poor self-control students often lack the consciousness of learning. There are some hard-working high school students make the mistake University is the end of studying, losing a clear goal and motivation. Therefore, the college students prone to be aimless on study, their mentality is empty and fidgety, and cannot through positive self-adjust to adapt to the learning environment, so cause weariness and lazy behaviors.

The Contradictions of Independent Consciousness and Dependence Psychology. Although the economy of college students showed strong dependence to the parents, but because of their "adult consciousness" gradually clear, they present a significant self-independence consciousness in ideology. They are no longer satisfied with the knowledge of the classroom, but concern about extracurricular activities, focusing on the culture of self-competence. With the enhancement of independent thinking and the ability of independent activities, they dare to evaluate social phenomenon and puts forward personal opinions; dare to emphasize on personal value, exert the role and expertise of individual. They with the attitude of ownership actively handling various tasks such as study, life and work, self-rights protection awareness significantly enhanced, dare to take legal weapon to protect their legitimate rights and interests. But there are some partial, childish and negative approach in the process, which lead to frustration and failure. College students' psychological fragility and poor frustration tolerance, they cannot use the appropriate way to release the pressure, cause various psychological problems finally. So in a way, this is the concentrated reflection of college students' self-contradiction.

The Networked of Interpersonal Communication. The rapid development of modern information technology, especially the growing popularity of the Internet, the network has penetrated into all aspects of the university, The Internet has gradually become the main mode of college students' learning and communicating. Network characteristic of fantasy and freedom can bring their ideas to meet and spiritual pleasure. But some students addict to them, easily fuzzy the essential difference between network and reality, often cause the distortion of the personality. It is not conducive to shape the outlook on life and values.

The Employment Pressure Caused Psychological Confusion. Nowadays, in intensely competitive society, college graduates increases every year, college students' employment pressure has become very serious. Particularly under the background of world financial crisis triggered by the US subprime mortgage crisis, the global economic development faces severe challenges, which has brought great pressure and challenge to the employment of college students. In front of the grim reality, college students are suffering from tremendous pressure. If this pressure cannot find an appropriate way to release, accumulate over a long period, some college students will be lost, confused, even fear.

\section{Exploration and Research on Psychological Health Education Management System}

Currently, the US, Japan, Britain and other countries has formed a relatively complete system of psychological health education, and has personnels of very high professional level, and included in school education. Our country should on the basis of learning from the advanced experience of foreign countries explore the psychological health education management system, which suitable to our national conditions and in accordance with the characteristics of college students, to make the education object from the past simply for students with psychological disorder extends to all students. It has important theoretical and practical significance to solve the psychological problems of the college students faced and confusion, promote the comprehensive development of their physical and 
psychological health, and promote the scientific, systematic and standardized of college students' psychological health education work.

Actively Creating a Good Atmosphere for Psychological Health Education. College students' psychological health education work is related to the stability and development of the school and personal growth of the students. It is a heavy and trivial work. The work cannot done well without high degree of responsibility [2]. Marshall McLuhan think medium is the message, the role of media in society is becoming increasingly important. Therefore, universities should fully give play to the role of media publicity, promote the psychological health knowledge through various ways and channels such as newspaper, television. Due to network broke the obstacles of space and time of people in the information communication, bring brand-new interpersonal interaction. Therefore, setting up the psychological health online on the Internet to give a full play to the superiority of the network. Through the establishment of love, study, employment, psychological testing, online chat, expert box plate to popularize knowledge of psychological health education for college students, For the events easy to induce the students psychological crisis, striving to have a detailed explanation throughout the entire event of before the incident, happen, happened. Thereby actively create a good atmosphere for psychological health education.

To Establish a High Quality of Psychological Health Education Team. It is difficult to adapt to the new situation of the students work without a high-quality team of psychological health education. The quality of foreign psychological health education practitioners is very high. These practitioners trained by the American Psychological Association (APA) and the National Association of School Psychology (NASP) two institutions, and obtain master's or doctoral degree can work in the school counseling in the United States. It can be seen that foreign country attach great importance to team Construction of psychological health education. Colleges should establish psychological health education network of four levels, that is play the role of four integral whole about "student cadres class tutors and student leaders - professional psychological counselors - classroom teachers” [3]. The establishment of a special combination, relatively stable, high-quality psychological health education team will play a crucial role for the college students' psychological health education [4].

To Create Psychological Health Education Curriculums. This not only is the main channel of school education, but also the main channel of university students' psychological health education [5]. Colleges can take the college students' psychological health education into the new compulsory course, teaching psychological health knowledge and psychological adjustment methods to college students through classroom teaching, in order to improve their ability to adapt to social life. University educational administration department should convene full-time teachers, counselors and students meeting to design the curriculum plan of psychological health education according to the characteristics of college students' psychological development. We can take the psychological health education into the compulsory courses for lower grade students, and open targeted elective courses, seminars and lectures for senior students.

The Establishment and Improvement of Students' Psychological Health Records. Establishing and improving the students' psychological health records have significant effect on college students' psychological health education, can understand the psychological status of freshmen in time, so that the work carried out targeted [6]. Establishing college students' psychological health records can also lay a solid foundation for developing the research on college students' psychological health, both complement each other.

To Strengthen the Network Security Management System. Internet is quietly changing the college students' learning, ways of thinking and life, affecting their political attitudes, moral character and value orientation. Now that network has become an important part of today's college students' study and life, We must adapt to the requirements of the network age, realize the innovation of managing means, take the initiative to occupy the new position of the network ideological and political education. We should fully understand the importance of strengthening and improving ideological and political work under the network environment, and actively explore the way of network ideological and political work. 
To Create a Good Campus Culture. The influence of campus culture on college students is subtle, and its function of educating people is self-evident. We can meet the demand of college students' psychological and spiritual through development of rich and colorful campus cultural life, and take the psychological health education into activities to effort to build the campus culture which meets the needs of students' development. Good campus culture environment can have a significant impact on the formation of students' knowledge, skills and personality. This can make the advantages of college students' psychological health education and ideological and political education complementary, and college students' psychological health education has a great role in promoting the construction of harmonious campus.

\section{Conclusion}

College students' psychological health is an eternal topic, is also the important content and the necessary conditions of cultivating high-quality talents. With the development of society and the progress of age, college education managers must keep pace with the ages, grasp the pulse of the development of the society, and understand college students' ideological dynamic, and combine the successful foreign experience, China's national conditions and characteristics of college students' psychological development. Using science college students' psychological health education management system to guide college students' all-round development in various aspects to better cultivate the qualified builders and reliable successors for socialism career.

\section{References}

[1] J.G. Lv, College students' psychological health education, M. Chengdu: Sichuan University Press. 2005:2. (In Chinese)

[2] S.H. Zheng, H. Jing and L.X. Wang, Strengthening college students' psychological health education and training college students' good psychological quality, N. Guangming Daily. 2005:8. (In Chinese)

[3] L. Cheng, Exploration and research on college students' psychological health education management system, J. Exploration of education. 2007, 4(2). (In Chinese)

[4] X.H. Chen, An introduction to the setback education, M. Hefei: China University of Science and Technology Press. 2006:116. (In Chinese)

[5] B.Q. Bian, The development and enlightenment of American school psychological guidance, J. Education practice and research. 2001, 12. (In Chinese)

[6] B.Y. Xie, College students' psychological health education and guidance, M. Changsha: Hunan University Press. 2005: 175. (In Chinese) 